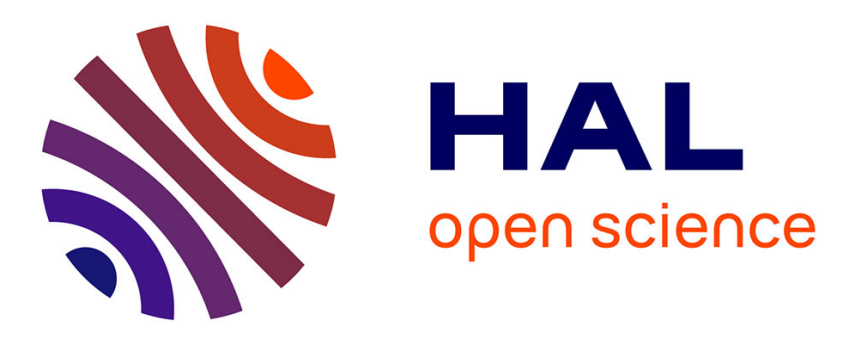

\title{
Fully coupled electrothermal and mechanical simulation of the production of complex shapes by spark plasma sintering
}

Antoine van Der Laan, Romain Epherre, Geoffroy Chevallier, Yannick Beynet, Alicia Weibel, Claude Estournès

\section{To cite this version:}

Antoine van Der Laan, Romain Epherre, Geoffroy Chevallier, Yannick Beynet, Alicia Weibel, et al.. Fully coupled electrothermal and mechanical simulation of the production of complex shapes by spark plasma sintering. Journal of the European Ceramic Society, 2021, 41 (7), pp.4252-4263. 10.1016/j.jeurceramsoc.2021.02.010 . hal-03215788

\author{
HAL Id: hal-03215788 \\ https://hal.science/hal-03215788
}

Submitted on 3 May 2021

HAL is a multi-disciplinary open access archive for the deposit and dissemination of scientific research documents, whether they are published or not. The documents may come from teaching and research institutions in France or abroad, or from public or private research centers.
L'archive ouverte pluridisciplinaire HAL, est destinée au dépôt et à la diffusion de documents scientifiques de niveau recherche, publiés ou non, émanant des établissements d'enseignement et de recherche français ou étrangers, des laboratoires publics ou privés. 


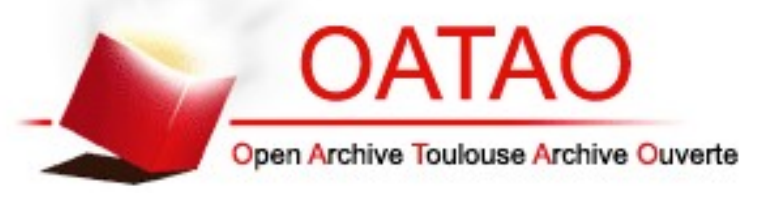

\section{Open Archive Toulouse Archive Ouverte}

OATAO is an open access repository that collects the work of Toulouse researchers and makes it freely available over the web where possible

This is an author's version published in: https://oatao.univ-toulouse.fr/27701

Official URL :

https://doi.org/10.1016/j.jeurceramsoc.2021.02.010

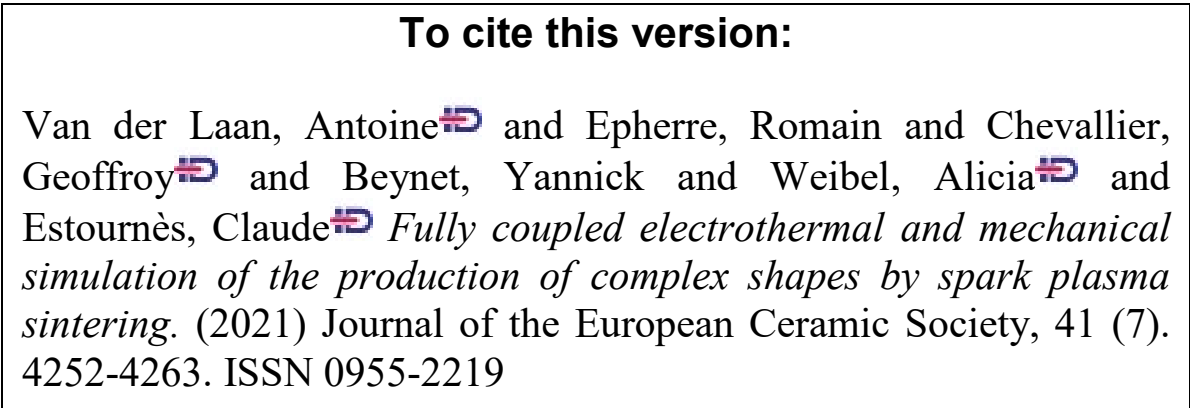

Any correspondence concerning this service should be sent to the repository administrator: tech-oatao@listes-diff.inp-toulouse.fr 


\title{
Fully coupled electrothermal and mechanical simulation of the production of complex shapes by spark plasma sintering
}

\author{
A. Van der Laan ${ }^{\mathrm{a}, \mathrm{b}}$, R. Epherre ${ }^{\mathrm{b}}$, G. Chevallier $^{\mathrm{a}}$, Y. Beynet ${ }^{\mathrm{b}}$, A. Weibel ${ }^{\mathrm{a}}$, C. Estournès ${ }^{\mathrm{a}, *}$ \\ ${ }^{\text {a }}$ CIRIMAT, Université de Toulouse, CNRS, Université Toulouse 3 - Paul- Sabatier, 118 Route de Narbonne, 31062 Toulouse cedex 9, France \\ ${ }^{\mathrm{b}}$ Norimat, 51 Rue de l'Innovation, 31670 Labège, France
}

\section{A R T I C L E I N F O}

\section{Keywords:}

Spark plasma sintering

Numerical modelling

Complex shapes

Creep parameters

\begin{abstract}
A B S T R A C T
The obtention of an accurate mechanical model of the spark plasma sintering (SPS) requires the identification of creep parameters. Those parameters are usually determined experimentally, which involves several tests and could be a source of error for the model predictions. A numerical identification, based on only one SPS experiment per material, allowed the determination of the creep parameters of $\mathrm{Al}_{2} \mathrm{O}_{3}$ and TiAl samples. The resulting mechanical model was then coupled with an electro-thermal model of the system to obtain a fully coupled simulation of the SPS. This model can predict the densification behavior not only of simple pellets, but also of complex shape configurations. It accurately predicts the density gradients inside the complex sintered parts as well as the interface distortion during sintering. Thus, numerical simulation can be used as an efficient predictive tool to obtain fully dense objects with the desired geometry.
\end{abstract}

\section{Introduction}

Spark plasma sintering (SPS) is an efficient technique used to produce fully dense materials at a faster rate compared to conventional techniques like hot pressing [1]. The main differences consist in the application of a uniaxial pressure and an electric current that heats up the system by Joule heating [2]. This allows to have fast heating rate and thus, to keep a fine microstructure in the final product, which can be particularly interesting to enhance the mechanical properties of the material [3-5]. One of the other benefits of the SPS is that it can be used to efficiently sinter a wide range of materials like refractory metals, intermetallics, ceramics or polymers [6].

For some years, due to the configuration of the SPS, it was only possible to produce simple shapes like pellets. Recently, several studies overcame this issue and were able to produce complex shapes by SPS [7-9]. The main problematic with complex shapes is the inhomogeneity of density induced by the uniaxial pressing [10]. Thus, several solutions were found like the use of a complex tooling [11] or adding a sacrificial part in order to compensate the lack of displacement (and thus sintering) in some areas of the part [10]. However, this solution would only work for very specific applications. In 2017, Manière et al. [7] developed a patented technique called Mobilint that uses a sacrificial counterpart which is separated from the powder by a mobile interface. This approach allows the production of almost any shape and any material provided that a suitable counter-part material is found.

Numerical simulation appears to be a promising tool to develop solutions to obtain fully dense complex shape objects with the desired geometry. Developing an accurate fully coupled Electro-ThermalMechanical (ETM) model of the SPS technique would be a great asset for this matter, as it can be used as a predictive tool. A simple method to obtain an accurate electro-thermal simulation of the production of both simple and complex shapes for any type of material was developed in a previous work [12]. This first step is essential to have a precise coupled model since the mechanical contribution (and especially the creep and sintering equations) strongly depends on the temperature field of the sample.

Several mechanical models, like the approach of Olevsky [13] or Abouaf [14], are available in the literature to describe the densification step. Each model requires the identification of creep parameters that will be developed later in this study. In most works, those parameters are identified experimentally, which requires a specific equipment and multiple experiments [15-18]. The objective of this study is to develop a new approach that will allow to identify numerically the creep parameters based on only one experimental trial per material. This will allow to rapidly obtain a fully coupled simulation of the SPS for both simple and complex shapes.

\footnotetext{
* Corresponding author.

E-mail address: estournes@chimie.ups-tlse.fr (C. Estournès).
} 


\section{Experimental and computational methodology}

\subsection{Materials and methods}

All the materials were spark plasma sintered using a Dr. Sinter 2080 unit, SPS Syntex Inc., (Japan,) available at the Plateforme Nationale CNRS de Frittage Flash located at the Universite Toulouse 3 Paul Sabatier (Toulouse, France).

The two different materials used, were one ultra-pure alumina $\left(\mathrm{Al}_{2} \mathrm{O}_{3}, 99.9 \%\right.$, spray-dried granulates with an average crystallite size of $150 \mathrm{~nm}$ and a mean granulate size of $35 \mu \mathrm{m}$, from Nanoe) and a titanium aluminide powder (TiAl-4822-9, with an average grain size of $75.4 \mu \mathrm{m}$, from Praxair).

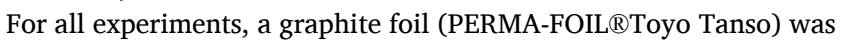
systematically placed to cover the inside wall of the die, as well as at the interfaces between the punches/sample and spacers/electrodes. A graphite felt is placed all around the outside wall of the die to minimize the heat loss during the experiment.

In order to keep the same conditions between the experiments, the same SPS cycle was applied for all trials. The control temperature is measured by a lateral pyrometer (IR-AH series Chino) focused inside a hole located in the outside wall of the die $(1.8 \mathrm{~mm}$ in diameter and $3 \mathrm{~mm}$ in depth). The setpoint temperature is regulated by the SPS machine through a PID regulation on the root mean square of the current delivered by the apparatus. The temperature is set at $600{ }^{\circ} \mathrm{C}$ for the first five minutes to initiate the first stage of the heating up of the apparatus. During these five minutes, the pressure is applied linearly up to $50 \mathrm{MPa}$. Then, the temperature of the die wall is set to increase at a rate of 100 ${ }^{\circ} \mathrm{C} / \mathrm{min}$ to the setpoint temperature. The SPS cycle performed is described in Fig. 1. In this study, no temperature holding time was added when the SPS setpoint is reached. To freeze (as much as possible) the density and geometry of the part as it is at the setpoint, the power is switch off in order to release the temperature and the pressure rapidly and simultaneously.

The first set of experiments aims to determine the creep laws of both studied materials: $\mathrm{Al}_{2} \mathrm{O}_{3}$ and TiAl. To do so, $3 \mathrm{~mm}$ thick pellets are SPSintered inside dies with inner diameter of $36 \mathrm{~mm}$ as illustrated in Fig. 2 (a). The trials consist in increasing the temperature until the sample is fully dense. For $\mathrm{Al}_{2} \mathrm{O}_{3}$ samples this temperature is around 1500 ${ }^{\circ} \mathrm{C}$ whereas it is about $1200{ }^{\circ} \mathrm{C}$ for TiAl samples. During each experiment, the displacement is recorded by means of a z-axis sensor located in the SPS device on the lower part of the column (i.e. electrode). To convert this displacement into the shrinkage of the sample due to its densification, once the first experiment is done (i.e. full density is reached), the SPS cycle is relaunched in the same conditions. The second cycle then gives the thermal expansion of both the column and the sample without the sintering contribution of the latter. Hence, by subtracting the two displacement curves it is possible to get the displacement induced by the sintering as shown in Fig. 3 (a). Knowing the final height and density of the sample it is possible to determine the evolution of the sample density during the SPS trial as illustrated in Fig. 3 (b).

The same methodology is used to determine the evolution of the density of $\mathrm{Al}_{2} \mathrm{O}_{3}$ and TiAl samples with a diameter of 20 and $8 \mathrm{~mm}$ and a final height of $3 \mathrm{~mm}$. These two configurations are described in Fig. 2 (b) and (c). Those trials are used to validate the approach developed on the $36 \mathrm{~mm}$ samples.

The second set of experiment consists in the sintering of a TiAl starshaped object using the Mobilint approach [7]. First, an $\mathrm{Al}_{2} \mathrm{O}_{3}$ counterpart is pressed (with an adequate punch) and then pre-sintered in a Nabertherm $\odot$ oven to give it a density compatible with the tapped density accessible with the TiAl powder used. This means that the sintering range of the part and the counterpart should coincide (as much as possible) in order to reduce the distortions in the final part. The role of this pre-sintering step is also to give the counterpart enough mechanical strength to facilitate its introduction in a graphite die. Prior TiAl powder introduction in the die a graphite layer is sprayed on the $\mathrm{Al}_{2} \mathrm{O}_{3}$ and plays the role of the mobile interface. The obtained assembly is illustrated in Fig. 2 (d). The objective of this set of experiments is to measure the final densities and geometries of star-shaped objects sintered at several temperatures and to compare them with the model predictions to assess its validity. Thus, eight SPS trials were realized at different temperatures between 950 and $1300{ }^{\circ} \mathrm{C}$ (every $50{ }^{\circ} \mathrm{C}$ ), as illustrated by the green points in Fig. 1. Preliminary experiments showed that the control temperature cannot be set higher than $1300{ }^{\circ} \mathrm{C}$, otherwise, due to the well-known temperature gradients in the tools, the temperature of the TiAl part is higher than its melting point.

For each experiment, after the separation between the counterpart and the star-shaped object (which is facilitated by the application of the graphite spray), both parts are characterized. Each part is analyzed using a 3D scanner (Zeiss Comet ${ }^{\circledR}$ ) with a $24 \mu \mathrm{m}$ resolution. After analysis on the software Zeiss Calypso ${ }^{\circledR}$, several geometrical data can be determined. As part of this study, the height of the star-shaped object and the cross section of the parts were measured as illustrated in Fig. 4 (b) and (d). As shown in Fig. 4 (c), it is possible to have access of the geometry (i. e. volume) of the object and hence its relative density. After geometrical characterization, the TiAl parts are cut in half, polished, and then observed with a scanning electron microscope (SEM) to determine the density gradients inside the samples.

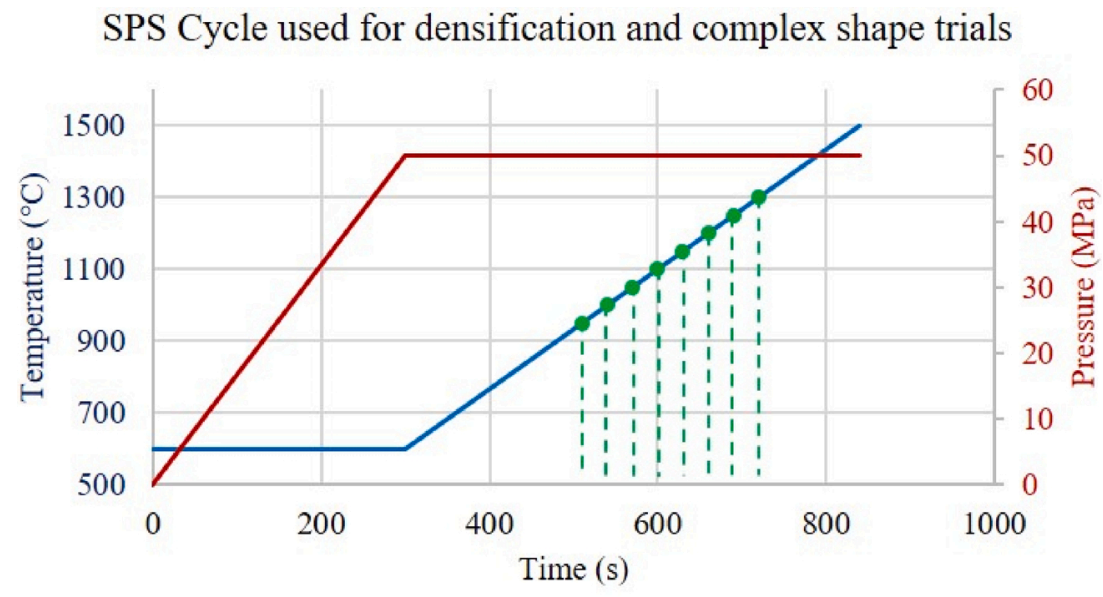

- Setpoint temperature - Complex shape trials — Applied pressure

Fig. 1. Description of the SPS cycle used for the several experiments. 
(a)

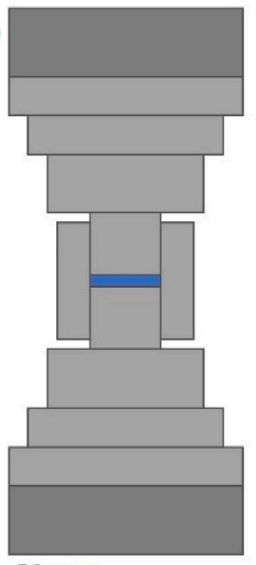

$50 \mathrm{~mm}$ (b)

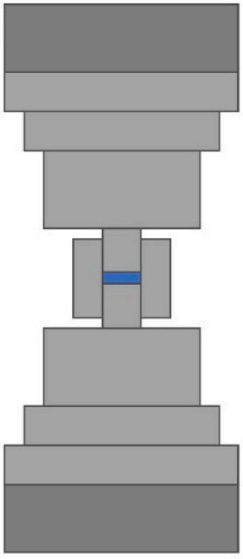

(c)

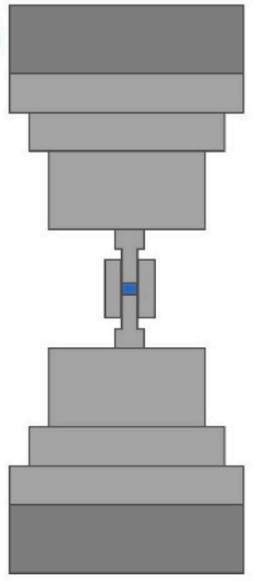

(d)

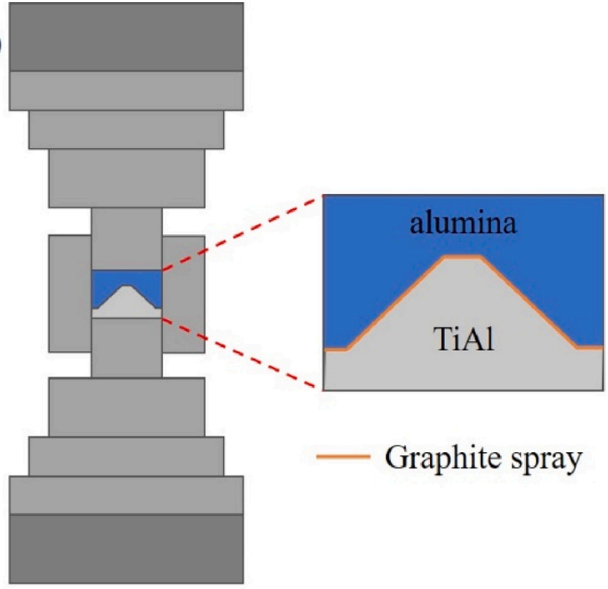

Fig. 2. SPS configurations used to sinter (a) a $36 \mathrm{~mm}$ sample, (b) a $20 \mathrm{~mm}$ sample, (c) a $8 \mathrm{~mm}$ sample and (d) a star shaped object.

\section{(a) SPS dilatometry experiment on a $36 \mathrm{~mm}$ alumina pellet}

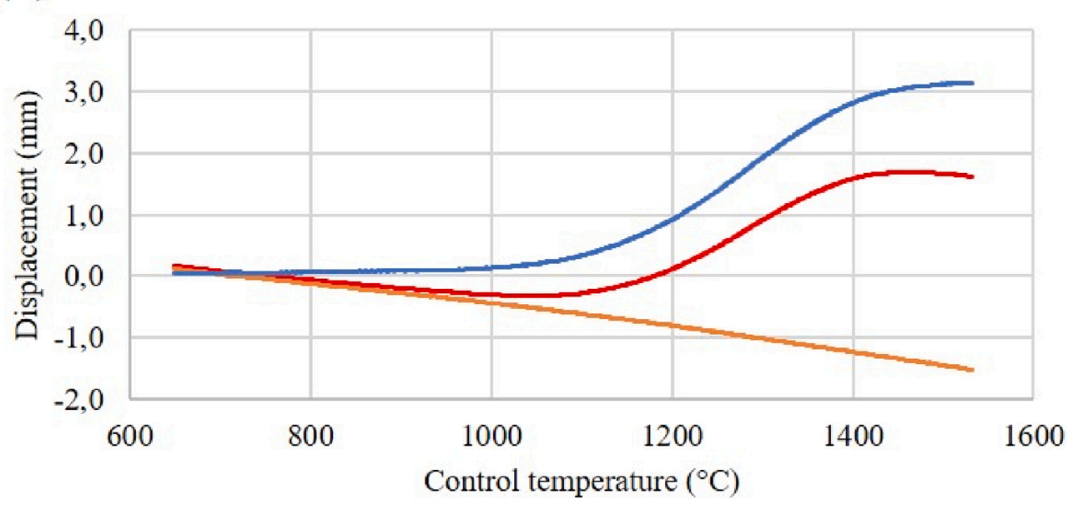

— SPS displacement — Thermal expansion — Sintering displacement

(b) Evolution of the density of a $36 \mathrm{~mm}$ alumina pellet during SPS

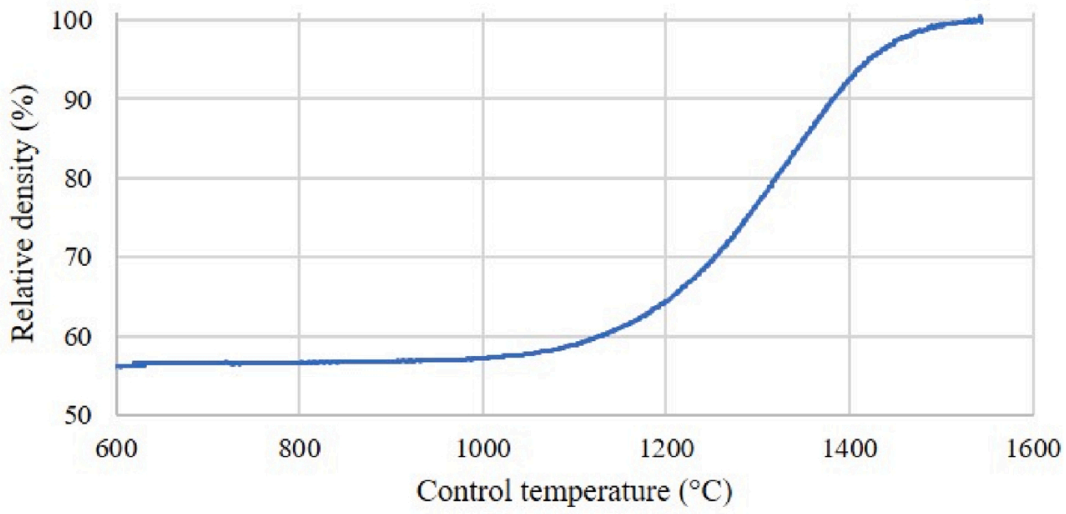

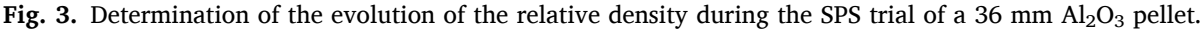

\subsection{Electro-thermal simulation}

The main goal of this work is to develop a fully coupled simulation of the SPS process. With the mechanical model it is possible to predict the creep and sintering behavior. However, the precision, and more important, the transferability of the model from an SPS configuration to another heavily rely on the accuracy of the electro-thermal model. The creep and densification mechanisms are directly linked to the temperature of the sample, as it will be developed in the next section. Thus, it is crucial to have an electro-thermal model that accurately describes the electric behavior and the evolution of the temperature in the entire SPS column and particularly the thermal gradients inside the samples since 
(a)

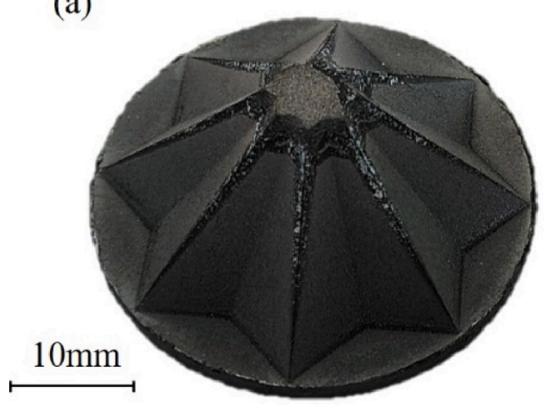

(b)

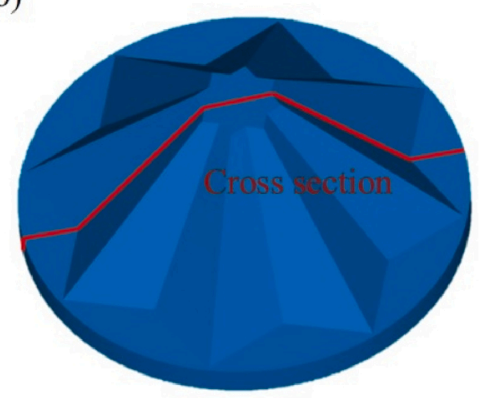

(c)

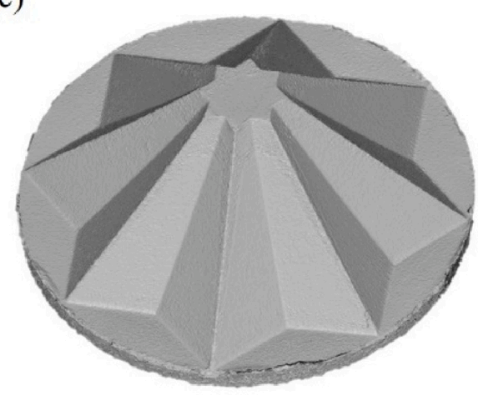

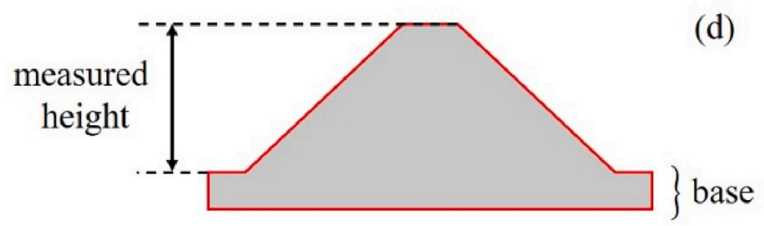

(d)

base

Fig. 4. (a) Picture of a TiAl star-shaped object sintered by SPS. (b) CAD of the star shaped part, (c) 3D scan of the star shaped object (d) Illustration of the measured height of the piece.

they will undergo most of the deformation.

Therefore, a previous study has been fully dedicated to the development of a simple method that allows to have a precise electro-thermal simulation of the SPS [12]. This method can be set up for almost any kind of material and SPS configuration (simple and complex shapes) with only a limited number of experimental tests. For example, Fig. 5 shows that the model gives a good prediction of the current through the column and the temperatures of both the TiAl star-shaped object and the $\mathrm{Al}_{2} \mathrm{O}_{3}$ counterpart. This good agreement between experimental and simulated values was obtained through only two experiments on simple shapes.

(a) Temperature of the TiAl - TiAl star-shaped object with alumina counter-part

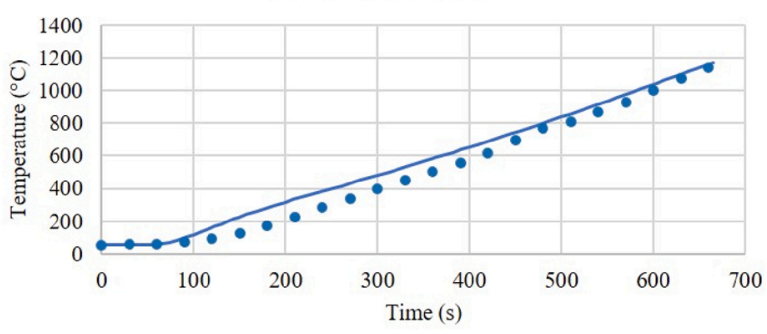

- Experimental Calculated

\subsection{Creep law and densification models}

In the literature there are several forms of the equation that describes the compressive creep mechanisms [15,19]. The model used in this work relies on the Norton-Green creep power law equation that was developed for dense visco-plastic materials [20]:

$\dot{\varepsilon}_{e q}=A \sigma_{e q}{ }^{n}$

Where $\dot{\varepsilon}_{\text {eq }}$ et $\sigma_{\text {eq }}$ are the equivalent strain rate and the equivalent stress. The parameter $\mathrm{n}$ is the power law creep exponent and $\mathrm{A}$ is a temperature dependent parameter defined as such:

(b) Temperature of the alumina - TiAl star-shaped object with alumina counter-part

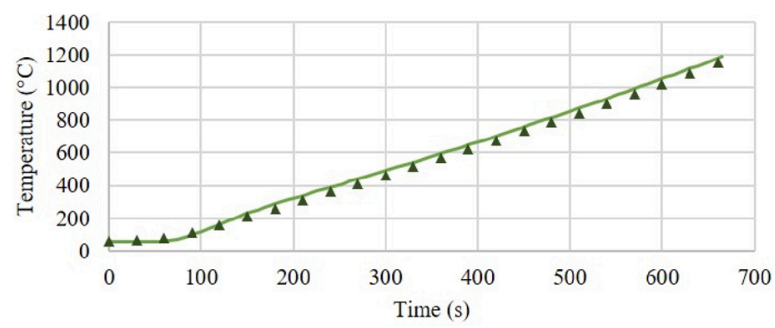

- Experimental Calculated

(c) Current delivered through the SPS column - TiAl star-

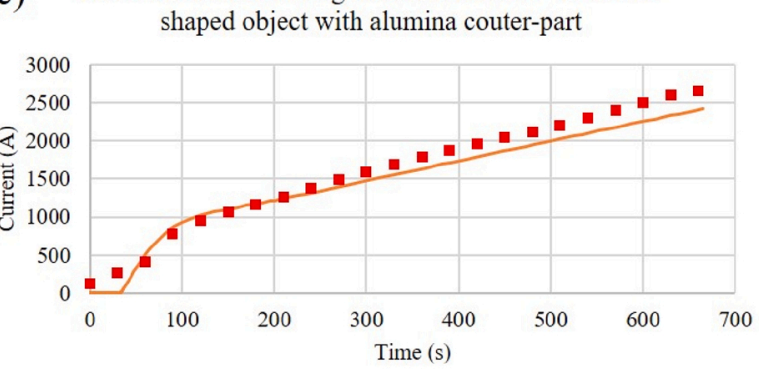

- Experimental Calculated

Fig. 5. Evolution of the temperature of the TiAl star-shaped object (a) and the $\mathrm{Al}_{2} \mathrm{O}_{3}$ counter-part (b) and the current (c) through the SPS column for the star-shaped object configuration [12]. 
$A=A_{0} \exp \left(-\frac{Q}{R T}\right)$

Where $\mathrm{A}_{0}$ is a pre-exponential factor, $\mathrm{Q}$ the creep activation energy, $\mathrm{R}$ the universal gas constant and the temperature.

For the remaining of the study the parameters $n, Q$ and $A_{0}$ will be referred as the creep parameters. Those three parameters need to be determined in order to describe the mechanical behavior of the SPS trials.

To be able to describe the densification of the sample during the SPS, a porosity consideration must be implemented in the creep model. To do so, two different approaches are used: the Olevsky [13] and the Abouaf [14] (or the Norton-Green) models. They both will be used since the mechanical model is based on previous works done on the same machine used for this study: Manière et al. [21] worked on $\mathrm{Al}_{2} \mathrm{O}_{3}$ samples with the Olevsky model whereas Martins et al. [22] studied the TiAl with the Abouaf model.

The Olevsky and the Abouaf approaches are fundamentally different but they both rely on the definition of a dissipative potential to express the stress tensor $\underline{\sigma}$ or the strain rate tensor $\underline{\dot{\varepsilon}}$ respectively. They also both introduce porosity functions. In the Olevsky model, the effective sintering stress of free sintering is neglected due to the application of high pressure $(50 \mathrm{MPa})$ and fast heating rate $\left(100^{\circ} \mathrm{C} / \mathrm{min}\right)$ [21]. The different equations used are summed up in Table 1.

Where $\rho$ is the density, $\dot{\gamma}$ and $\dot{e}$ are the invariants of the strain rate tensor, and $I_{1}$ and $J_{2}$ are the invariants of the stress tensor defined as follow:

$$
\left\{\begin{array}{c}
\dot{e}=\operatorname{tr}(\underline{\dot{\varepsilon}})=\dot{\varepsilon}_{x}+\dot{\varepsilon}_{y}+\dot{\varepsilon}_{z} \\
\dot{\gamma}=\sqrt{2\left(\dot{\varepsilon}_{x y}^{2}+\dot{\varepsilon}_{x y}^{2}+\dot{\varepsilon}_{x y}^{2}\right)+\frac{2}{3}\left(\dot{\varepsilon}_{x}^{2}+\dot{\varepsilon}_{y}{ }^{2}+\dot{\varepsilon}_{z}{ }^{2}\right)-\frac{2}{3}\left(\dot{\varepsilon}_{x} \dot{\varepsilon}_{y}+\dot{\varepsilon}_{x} \dot{\varepsilon}_{z}+\dot{\varepsilon}_{y} \dot{\varepsilon}_{z}\right)} \\
I_{1}=\operatorname{tr}(\underline{\sigma})=\sigma_{x}+\sigma_{y}+\sigma_{z} \\
J_{2}=\frac{1}{6}\left(\left(\sigma_{x}-\sigma_{y}\right)^{2}+\left(\sigma_{x}-\sigma_{z}\right)^{2}+\left(\sigma_{y}-\sigma_{z}\right)^{2}+6\left({\sigma_{x y}}^{2}+{\sigma_{x z}}^{2}+\sigma_{y z}{ }^{2}\right)\right)
\end{array}\right.
$$

In the expressions of the stress tensors (for both the Olevsky and
Abouaf models), the ratio $\frac{\sigma_{e q}}{\bar{\varepsilon}_{e q}}$ can be expressed with Eqs. (1) and (2).

One of the main differences between the two approaches is that for the Olevsky model, the porosity functions can be applied for any kind of material, whereas the Abouaf model requires an identification of the parameters $\alpha, \beta$ and $\mathrm{K}_{\mathrm{f}}$ for each material considered. This identification requires an experimental campaign [23], but this approach gives a more precise result. It has been reported in the literature that the Olevsky porosity functions could introduce some errors in the predictions of the model $[24,25]$. Then, it is preferable to use Abouaf's approach since it corresponds more accurately to the sintering behavior of the material. Thus, the porosity functions $\mathrm{c}$ and $\mathrm{f}$ were experimentally determined by Martins et al. [23] for the TiAl:

$\left\{\begin{array}{c}f=4.97\left(\frac{1-\rho}{\rho-0.52}\right)^{1.51} \\ c=1+2.9 f\end{array}\right.$

In some works, the grain growth is considered in the mechanical model $[14,26,27]$. Here, it is neglected as a first approximation due to the fast heating rate and the fact that the temperature is not held at the end of the trial to limit the apparition of grain growth.

\subsection{Numerical simulation and determination of the creep parameters}

All the computational work was performed using a finite element analysis on the Comsol Multiphysics $\odot$ software. The model used in this work is a continuation of the one developed in a previous study [12], using the same electrothermal limit conditions.

The electrical, thermal, and mechanical properties used in the model for the different materials are presented in Table 2 [28]. The properties of the graphite foil slightly differ from the bulk graphite. According to the producer Toyo Tanso $\odot$, the electrical and thermal conductivity are respectively about 40 and 140 times superior parallel to the surface of the foil compared to the bulk properties. Moreover, the porosity dependence of the properties of the $\mathrm{Al}_{2} \mathrm{O}_{3}$ and $\mathrm{TiAl}$ samples were added according to the work of Orrù et al. [6].

For the $\mathrm{Al}_{2} \mathrm{O}_{3}$ and TiAl pellets, the problem is $2 \mathrm{D}$-axisymmetric, which allows to simplify the calculations and reduces the computing

Table 1

Equations used for the Olevsky and Abouaf models.

\begin{tabular}{|c|c|c|}
\hline & Olevsky model & Abouaf model \\
\hline Stress tensor & $\dot{\dot{\varepsilon}}=\frac{\dot{\varepsilon}_{e q}}{\sigma_{e q}}\left(\frac{1}{\varphi} \underline{\sigma}+\left(\frac{1}{9 \psi}-\frac{1}{3 \varphi}\right) I_{1} \rrbracket\right)$ & $\dot{\dot{\varepsilon}}=\frac{\dot{\varepsilon}_{e q}}{\sigma_{e q}}\left(\frac{3}{2} c \underline{\sigma}+\left(f-\frac{1}{2} c\right) I_{1} \rrbracket\right)$ \\
\hline Equivalent parameter & $\dot{\varepsilon}_{e q}=\sqrt{\frac{\rho \dot{\gamma}^{2}+\psi \dot{e}^{2}}{\rho}}$ & $\sigma_{e q}=\sqrt{3 c J_{2}+f I_{1}^{2}}$ \\
\hline \multirow{2}{*}{ Porosity functions } & $\varphi=\rho^{2}$ & $f=K_{f}\left(\frac{1-\rho}{\rho-\rho_{c r}}\right)^{\beta}$ \\
\hline & $\psi=\frac{2}{3} \frac{\rho^{3}}{1-\rho}$ & $c=1+\alpha f$ \\
\hline Conservation of mass & $\frac{\dot{\rho}}{\rho}=-\frac{\dot{\varepsilon}_{e q} I_{1}}{3 \psi \sigma_{e q}}$ & $\frac{\dot{\rho}}{\rho}=-\frac{3 \dot{\varepsilon}_{e q} f I_{1}}{\sigma_{e q}}$ \\
\hline
\end{tabular}

Table 2

Physical properties of inconel, graphite, alumina and TiAl.

\begin{tabular}{|c|c|c|c|c|}
\hline & Inconel & Graphite & Alumina & TiAl \\
\hline Heat capacity $\left(\mathrm{J} \mathrm{kg}^{-1} . \mathrm{K}^{-1}\right)$ & $344+2.50 \times 10^{-1} \mathrm{~T}$ & $34.27+2.72 \mathrm{~T}-9.60 \times 10^{-4} \mathrm{~T}^{2}$ & 850 & $583+9.40 \times 10^{-2} \mathrm{~T}$ \\
\hline $\begin{array}{l}\text { Thermal conductivity (W.m-1. } \\
\mathrm{K}^{-1} \text { ) }\end{array}$ & $10.1+1.57 \times 10^{-2} \mathrm{~T}$ & $123-6.9910^{-2} \mathrm{~T}+1.55 \times 10^{-5} \mathrm{~T}^{2}$ & $39500 \mathrm{~T}^{-1.26}$ & $9.47+1.19 \times 10^{-2} \mathrm{~T}$ \\
\hline Electrical resistivity $(\Omega . \mathrm{m})$ & $\begin{array}{l}9.82 \times 10^{-7}+1.60 \times 10^{-10} \\
T\end{array}$ & $\begin{array}{l}1.70 \times 10^{-5}-1.87 \times 10^{-8} \mathrm{~T}+1.26 \times 10^{-11} \mathrm{~T}^{2}-2.44 \times 10^{-15} \\
\mathrm{~T}^{3}\end{array}$ & $\begin{array}{l}8.70 \times 10^{19} \\
\mathrm{~T}^{-4,82}\end{array}$ & $\begin{array}{l}4.06 \times 10^{-7}+6.45 \times 10^{-10} \\
T\end{array}$ \\
\hline Young's modulus (GPa) & 204 & 13 & 400 & 120 \\
\hline Poisson's coefficient & 0.32 & 0.2 & 0.22 & 0.34 \\
\hline Density $\left(\mathrm{kg} . \mathrm{m}^{-3}\right)$ & 8430 & $1904-0.01414 \mathrm{~T}$ & 4010 & 3960 \\
\hline
\end{tabular}


time. For the star-shaped object, even though the calculation was done in $3 \mathrm{D}$ the problem could be approximated by a $2 \mathrm{D}$ axisymmetric one. With this simplification, the star-shaped object would be approached by a cone, but it would not affect the data considered in this work (density and height of the part). A comparison between the two calculations (3D and 2D-axisymmetric) showed differences of less than $1 \%$ in terms of density or geometrical features. Both configurations were treated in Comsol as a union.

For both configurations (pellets and star-shaped object) the mesh is crucial for the accuracy and the efficiency of the calculation. The assembly was meshed using triangular elements and the size of the elements was chosen to be finer in the zones of interests like the samples.

The densification trials made on pellets were realized to determine the creep parameters $\mathrm{n}, \mathrm{Q}$ and $\mathrm{A}_{0}$ discussed in the previous section. Usually, the creep parameters are experimentally determined in-situ with creep tests on dense samples at a fixed temperature [21,23]. This identification strongly relies on the interpretation of a linear regression of the power creep law, which could affect the accuracy of the model. To avoid this experimental source of error, the (n, $\mathrm{Q}, \mathrm{A}_{0}$ ) parameters were directly optimized in the simulation, using reverse engineering to best fit the densification curve described in Fig. 3 (b). For each set of parameters ( $n, Q, A_{0}$ ) the calculated evolution of the density is compared to the experimental one, which allows to find the triplet that fits best the experimental data. The benefit of this approach is that it only requires a densification trial of a porous pellet (for each material considered) in the actual SPS conditions.

\section{Results and discussion}

The end goal of this work is to obtain an accurate fully coupled simulation of the sintering of complex shapes by SPS. The method developed here is to determine by reverse analysis the creep parameters of both $\mathrm{Al}_{2} \mathrm{O}_{3}$ and $\mathrm{TiAl}$ on simple porous pellets using an optimization algorithm. Then, those parameters are implemented into a complex configuration (star-shaped object) simulation to see if it gives accurate results in terms of density and geometry for both the $\mathrm{Al}_{2} \mathrm{O}_{3}$ counterpart and the TiAl object.

\subsection{Numerical identification of the creep parameters}

Fig. 6 shows the comparison between the experimental and calculated values of the density of both the $\mathrm{Al}_{2} \mathrm{O}_{3}$ and the TiAl pellets during the SPS trials. As mentioned previously, the sintering model chosen for the $\mathrm{Al}_{2} \mathrm{O}_{3}$ uses the Olevsky approach like in the work of $\mathrm{C}$. Manière et al. [21], whereas it uses the Abouaf approach for the TiAl sample similarly to the study of D. Martins et al. [22]. The porosity functions required by the Abouaf approach are described in Eq. (4) [23].

The optimization algorithm is able to find a triplet of creep

(a)

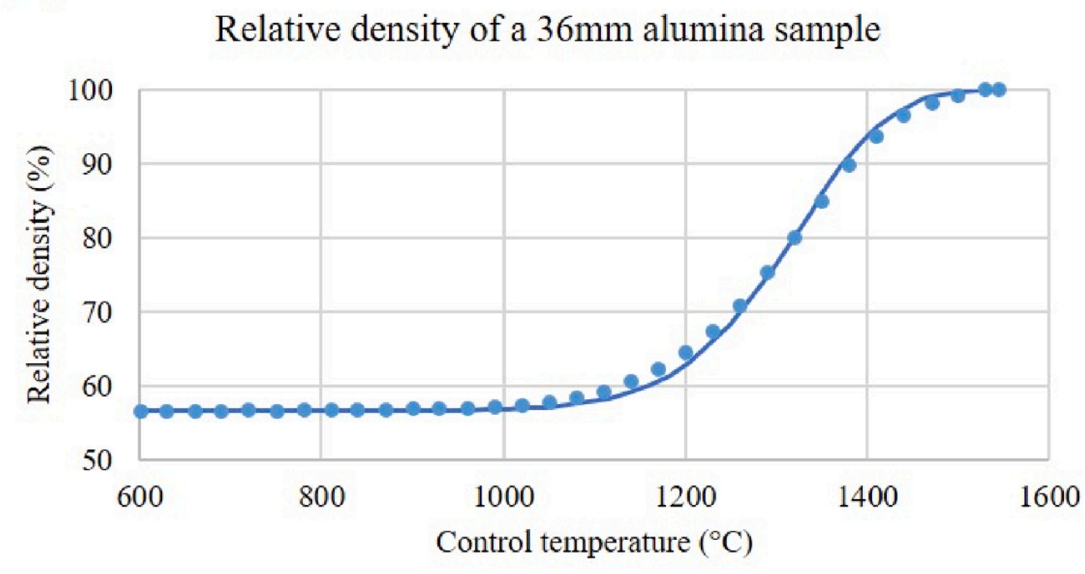

- Experimental Calculated

(b) Relative density of a $36 \mathrm{~mm}$ TiAl sample

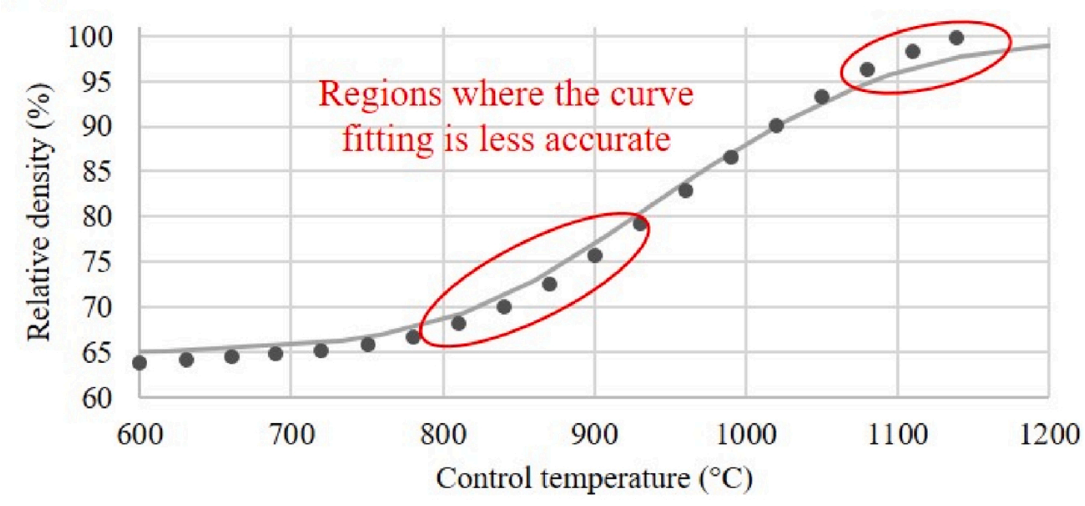

- Experimental Calculated

Fig. 6. Comparison between the experimental and calculated relative density of an (a) $\mathrm{Al}_{2} \mathrm{O}_{3}$ and (b) $\mathrm{TiAl} 36 \mathrm{~mm}$ samples. 
(a) Curve fitting of the beginnig of the densification curve of a $36 \mathrm{~mm}$ TiAl sample

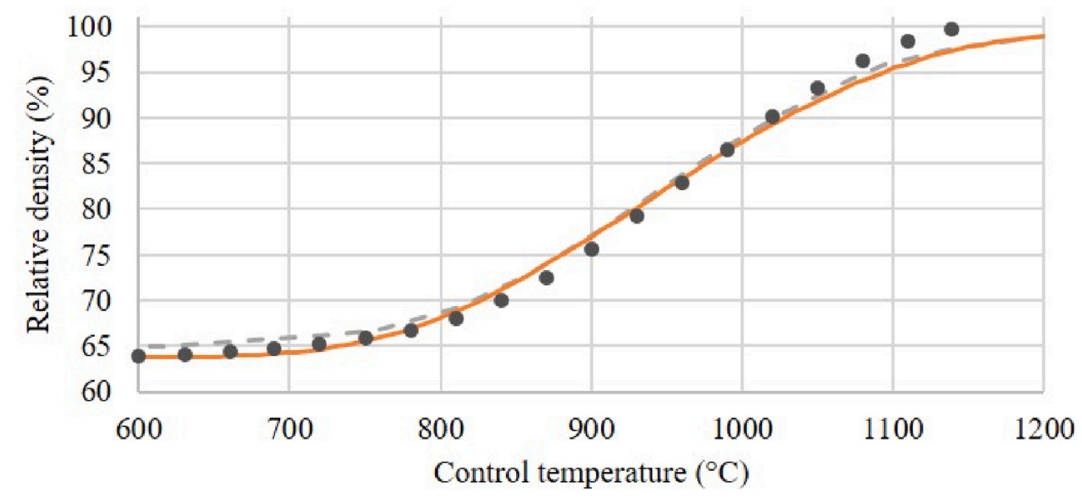

- Experimental - - - Fitting the full data - Fitting the beginning

\section{(b) Curve fitting of the end of the densification curve of a $36 \mathrm{mmTiAl}$ sample}

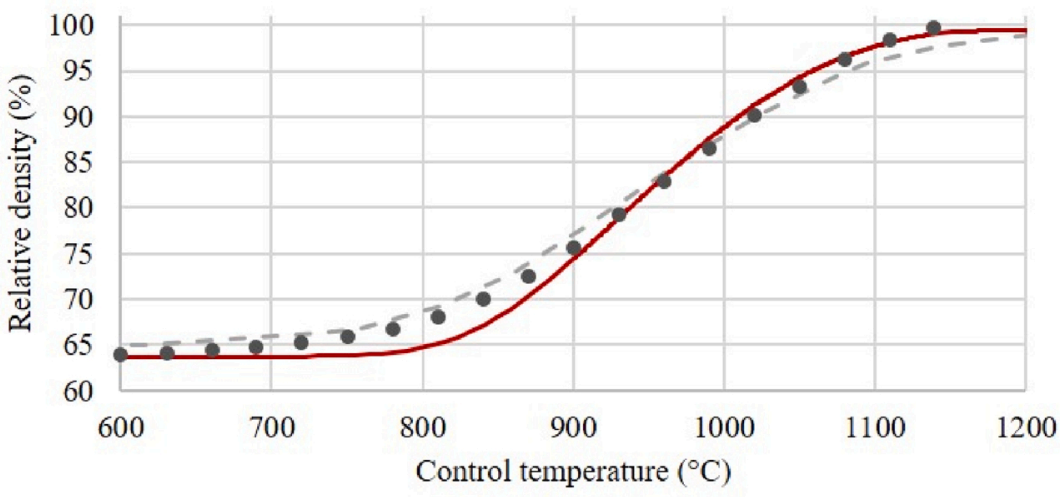

- Experimental - - - Fitting the full data - Fitting the end

Fig. 7. Curve fitting done on (a) the beginning and (b) the end of the densification curve of a TiAl $36 \mathrm{~mm}$ samples.

parameters that allows to fit the densification curve of the $\mathrm{Al}_{2} \mathrm{O}_{3}$ sample quite accurately. For the TiAl sample, even if the calculations are quite accurate overall, there are regions (at the beginning and at the end of densification) where the experimental curve slightly diverge from the calculated one as illustrated in Fig. 6.

It was not possible to find a good triplet that perfectly fits the whole curve. The fact that not only one but several mechanisms could occur during densification could be a potential explanation. If only the region of interest (i.e. the density below or above $80 \%$ for the TiAl) are considered for the optimization, it is possible to fit the density in those regions as illustrated in Fig. 7. Thus, it is likely that different mechanisms occur simultaneously during the SPS of those materials as it has

Table 3

Creep parameters for the $\mathrm{Al}_{2} \mathrm{O}_{3}$ and TiAl samples and the corresponding values found in the literature.

\begin{tabular}{lllll}
\hline & & $\mathrm{n}$ & $\mathrm{Q}(\mathrm{kJ} / \mathrm{mol})$ & $\mathrm{A}_{0}\left(\mathrm{~s}^{-1} \cdot \mathrm{Pa}^{-\mathrm{n}}\right)$ \\
\hline \multirow{2}{*}{$\mathrm{Al}_{2} \mathrm{O}_{3}$} & Full densification curve & 1.57 & 197 & $1.11 \times 10^{-8}$ \\
& C. Manière et al. [21] & 1 & $150-200$ & $\mathrm{~N} / \mathrm{A}$ \\
& Full densification curve & 1.63 & 237 & $1.68 \times 10^{-8}$ \\
\multirow{2}{*}{$\mathrm{TiAl}$} & Densification $<80 \%$ & 1.57 & 220 & $3.76 \times 10^{-9}$ \\
& Densification $>80 \%$ & 2.57 & 446 & $3.17 \times 10^{-9}$ \\
& D. Martins et al. [23] & 2.81 & 414 & $4.33 \times 10^{-9}$ \\
\hline
\end{tabular}

also been raised in the literature [22,29]. A way to improve the model would be to combine at least two mechanisms to describe the densification. However, as a first approximation and not to overload the model, the densification curves are fitted with only one mechanism, which led to the calculated curve in Fig. 6.

The different sets of creep parameters found for both $\mathrm{Al}_{2} \mathrm{O}_{3}$ and TiAl are presented in Table 3. By comparison, the activation energy for the $\mathrm{Al}_{2} \mathrm{O}_{3}$ is in the same order of magnitude with the ones from the study of C. Manière et al. [21]. There is a slight difference for the creep exponent, but it comes from the fact that they chose $\mathrm{n}$ as an integer in their study. The creep parameters determined for the end of densification of the TiAl are also comparable to the ones calculated by Martins et al. [22]. This shows the validity of the numerical approach, since both these works were done on the same machine and in the same SPS conditions. Thus, the creep parameters can be determined both numerically and experimentally. However, the numerical approach developed in this work has the benefit of being based on only one single trial, directly on the powder sample, which fits the actual SPS conditions. On the contrary, the experimental method relies creep tests, which consists in free compaction trials at several constant temperatures with different levels of stress per temperature [23]. 
(a) Relative density of an $8 \mathrm{~mm}$ alumina sample

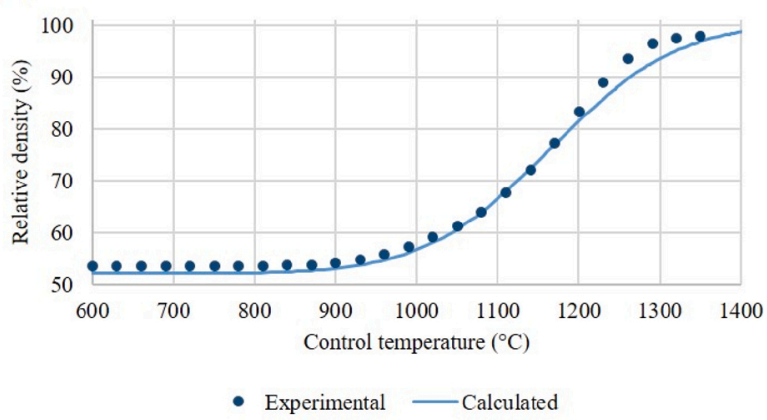

(c)

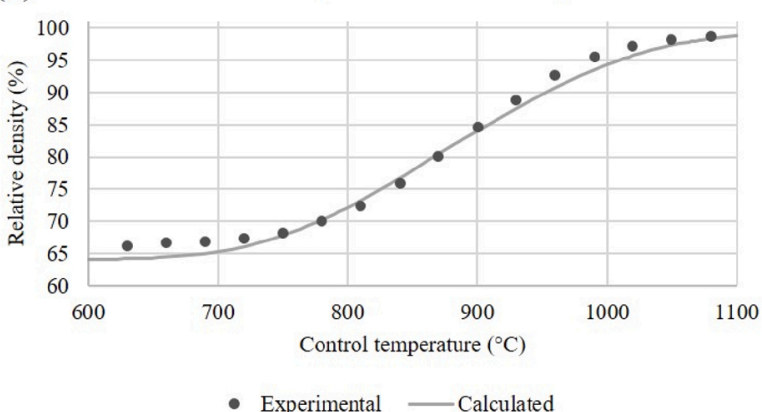

(b) Relative density of a $20 \mathrm{~mm}$ alumina sample

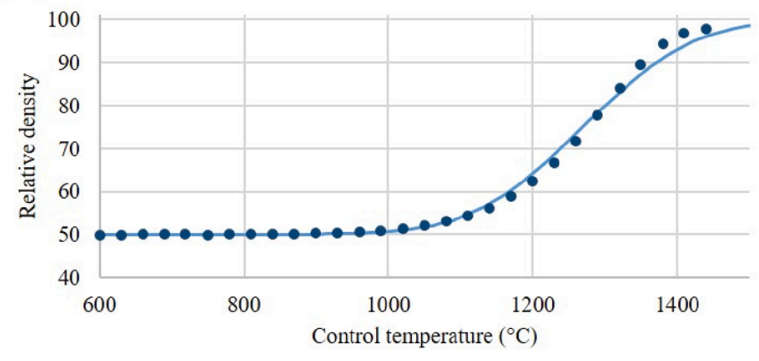

- Experimental Calculated

(d) Relative density of a $20 \mathrm{~mm}$ TiAl sample

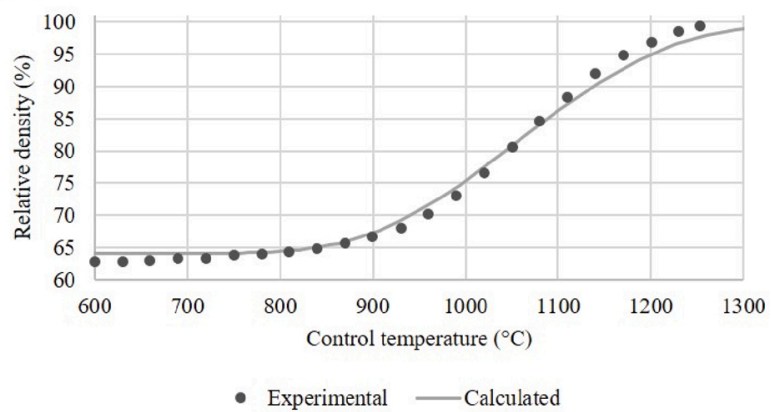

Fig. 8. Comparison between the experimental and calculated relative densities of (a) an $8 \mathrm{~mm}$ and (b) a $20 \mathrm{~mm} \mathrm{Al}_{2} \mathrm{O}_{3}$ samples, and of (c) an $8 \mathrm{~mm}$ and (d) a $20 \mathrm{~mm}$ TiAl samples.

\subsection{Testing the model on other simple configurations}

The creep equation directly depends on the temperature (as showed in Eqs. (1) and (2)), however the pressure and the heating rate are implicitly contained in the values of the creep parameters. Thus, if the electro-thermal model is accurate enough, the creep parameters should be identical for the 8,20 and $36 \mathrm{~mm}$ samples as for any die size. So, to validate the triplet of parameters $\left(\mathrm{n}, \mathrm{Q}, \mathrm{A}_{0}\right.$ ) calculated previously for both $\mathrm{Al}_{2} \mathrm{O}_{3}$ and TiAl samples with a diameter of $36 \mathrm{~mm}$, they are tested on two other configurations with an $8 \mathrm{~mm}$ and a $20 \mathrm{~mm}$ die sizes detailed in Fig. 2 (b) and (c).

Fig. 8 shows the comparison between the experimental and calculated results. The creep parameters chosen for the simulation are the one obtain with the optimization on the full densification curve in Table 3. The good fit of the experimental curve by the model shows the validity and the transferability of this approach from one configuration to another.

\subsection{Testing the model on a complex shape}

The end goal of this work is to model the electro-thermal and mechanical behavior of a complex shape. To do so, the creep parameters determined for the $\mathrm{Al}_{2} \mathrm{O}_{3}$ and the TiAl are implemented into the simulation of the SPS of a star-shaped object. The predicted density and geometry of both the TiAl part and the $\mathrm{Al}_{2} \mathrm{O}_{3}$ counterpart were compared to the experimental trials obtained at different temperatures between 950 and $1300{ }^{\circ} \mathrm{C}$ (control temperature).

\subsubsection{Density predictions}

Fig. 9 shows the experimental densities determined with the 3D scanner and the numerically calculated ones. The solid line corresponds to the evolution of the calculated density up to the maximum temperature the system could reach. For a control temperature (measured on the outside wall of the die) over $1300{ }^{\circ} \mathrm{C}$, the TiAl would start melting, which could deteriorate the SPS tooling.

The experimental results are in a very good agreement with the

Density of the TiAl part and the alumina counterpart

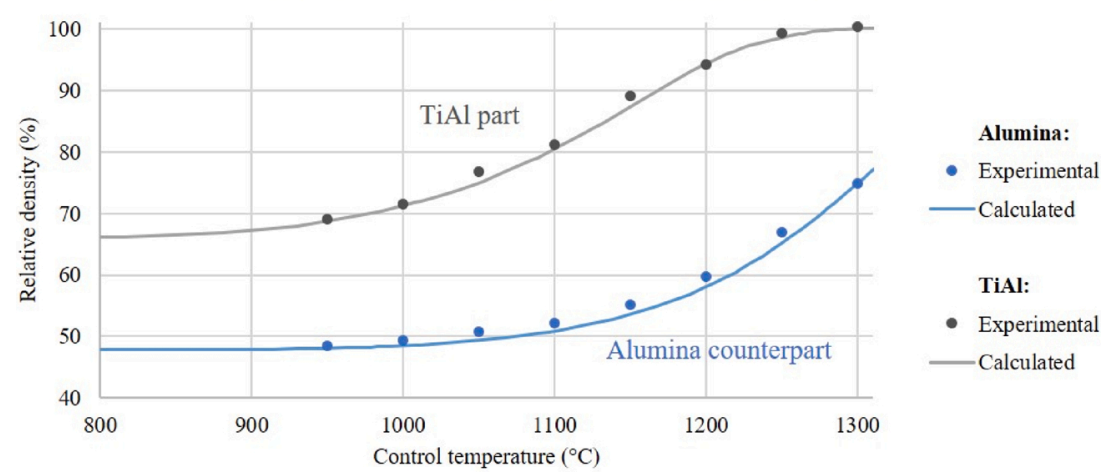

Fig. 9. Comparison between the relative densities of the TiAl star shaped object and the $\mathrm{Al}_{2} \mathrm{O}_{3}$ counterpart. 


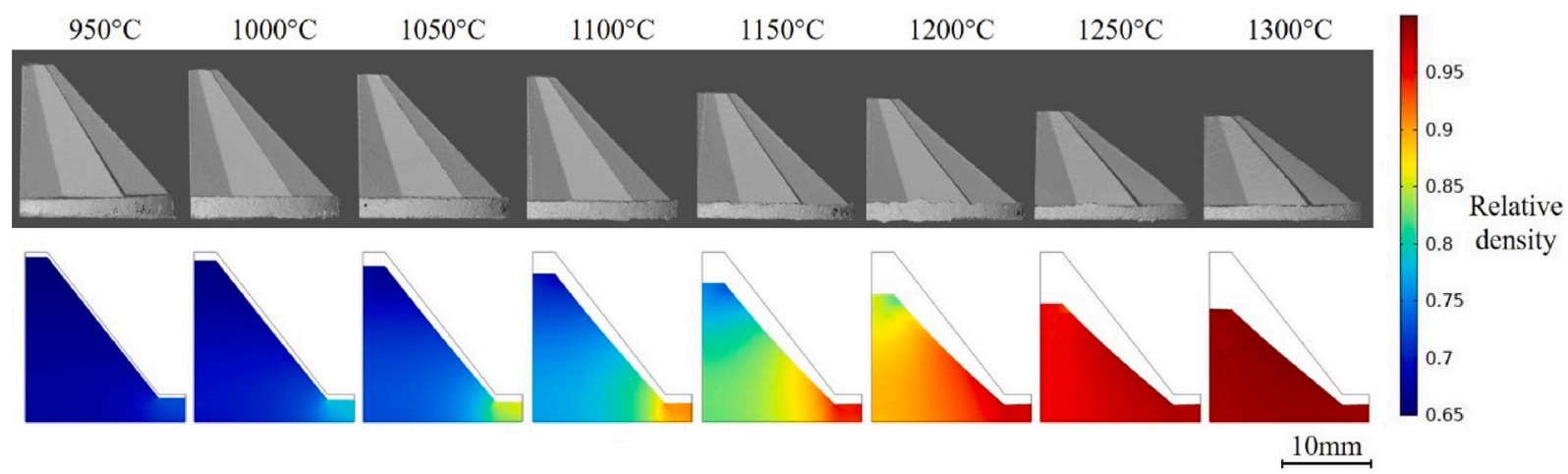

Fig. 10. Calculated density gradients inside the TiAl parts produced at different sintering temperatures.

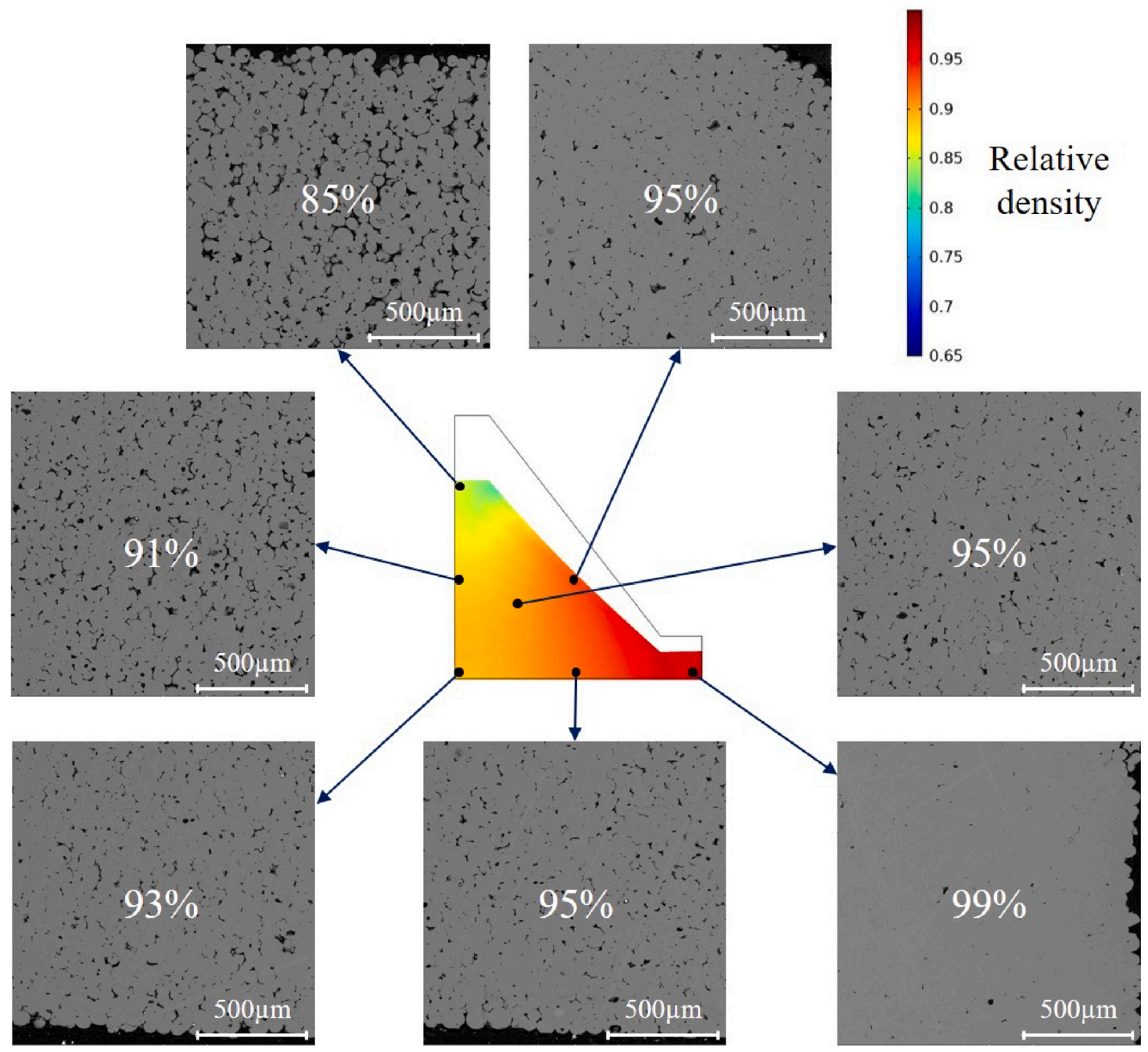

Fig. 11. Comparison between the predicted and measured density at several points of a TiAl star-shaped object sintered at $1200{ }^{\circ} \mathrm{C}$.

model for both the star-shaped object and the counterpart. It appears that the TiAl part is fully dense for a sintering temperature above 1300 ${ }^{\circ} \mathrm{C}$, whereas the counterpart reaches a $75 \%$ densification at $1300{ }^{\circ} \mathrm{C}$.

However, this is only an overall estimation of the density. The model is also able to predict the density gradient inside the parts along the sintering as illustrated in Fig. 10. The comparison between the simulated and the experimental density gradients for a part sintered at $1200{ }^{\circ} \mathrm{C}$ is presented in Fig. 11. The densities predicted locally inside the TiAl part by the model are in a good agreement with the one measured on the SEM image. It appears that the outside of the base is the part that will sinter first compared to the rest of the object, which was predicted by the model. The last part of the object to reach full density is the very top as it 


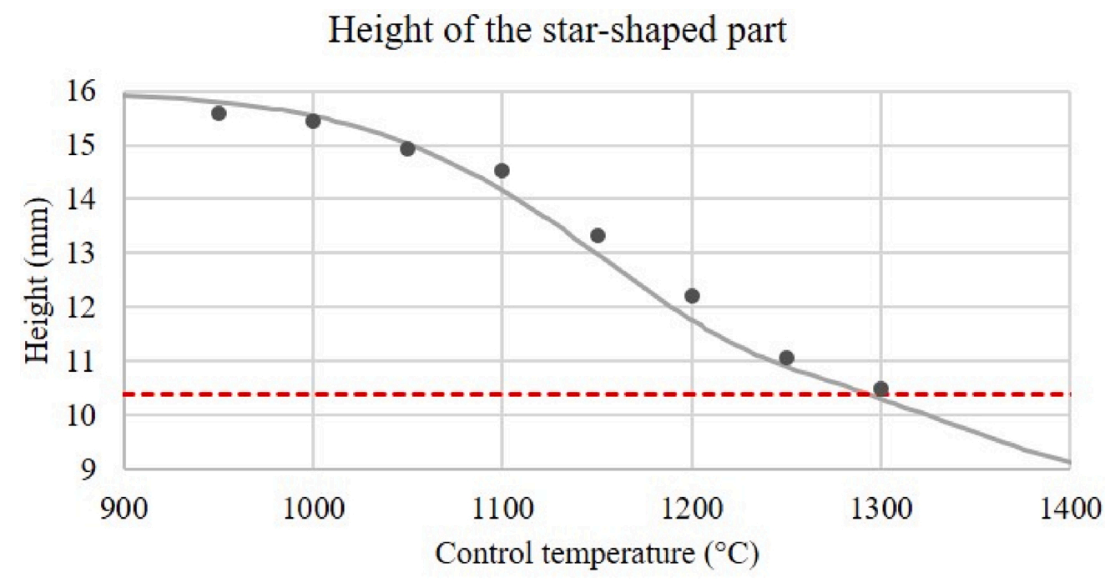

- Experimental Calculated -----Targeted height

Fig. 12. Comparison between the calculated and measured height of the TiAl star shaped object.

can be seen on the sample sintered at $1200^{\circ} \mathrm{C}$.

Thus, the model is not only able to accurately calculate the overall density of the TiAl and the $\mathrm{Al}_{2} \mathrm{O}_{3}$ counterpart. It can also predict the density gradients inside the parts along the sintering of the complex shape. This is very helpful to better understand the sintering mechanisms that occurs during the SPS of such pieces, in order to have a better control on the final product.

\subsubsection{Geometrical considerations}

The calculated and measured heights of the TiAl parts sintered at different temperatures are presented in Fig. 12. The initial height of the part is $16 \mathrm{~mm}$ and the TiAl powder has an initial relative density of $65 \%$. Thus, the targeted height, considering a uniaxial displacement is 10.4 $\mathrm{mm}$ (red dotted line in Fig. 12). It is clearly evidenced that the model can quite accurately predict the evolution of the uniaxial displacement of the part that occurs during sintering, and shows that the targeted height is reached for a sintering temperature of $1300^{\circ} \mathrm{C}$. At this temperature, the object is fully dense and has reached the desired dimension.

The cross section of the star-shaped object sintered at $1300{ }^{\circ} \mathrm{C}$ is presented in Fig. 13 (c). On the 3D scan, the gap between the theoretical shape (only due to uniaxial displacement and with a height of $10.4 \mathrm{~mm}$ ) and the 3D scan has been magnified by a factor of 20 to be visible. (a)

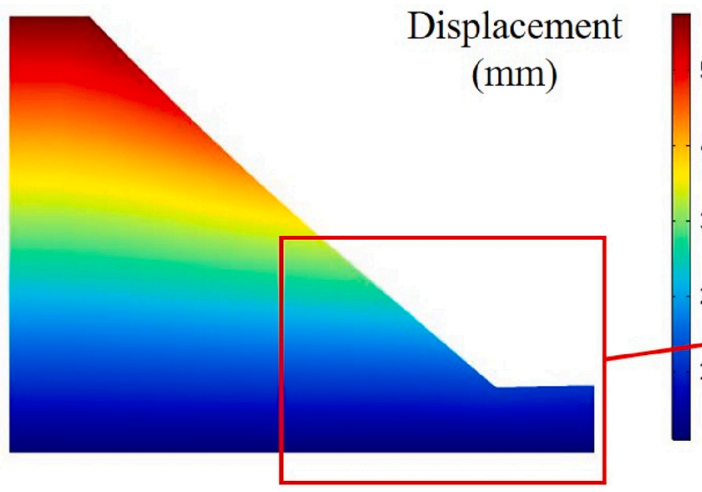

(c)

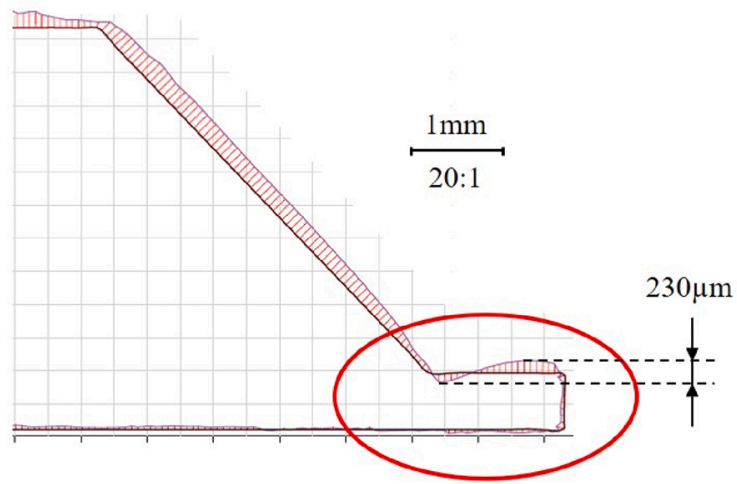

(d)

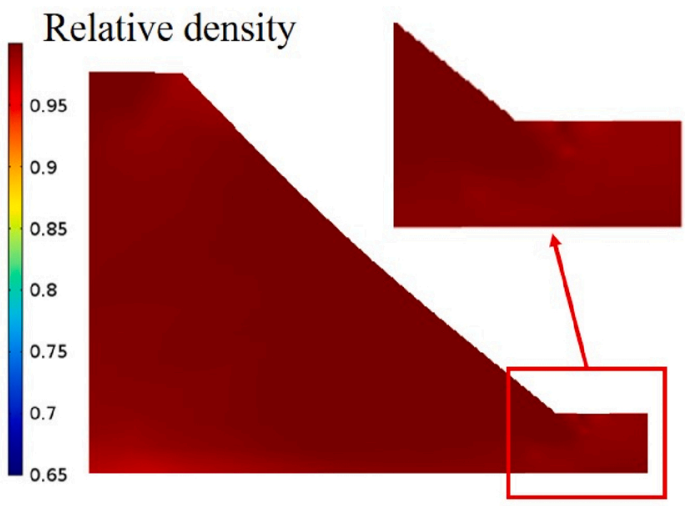

Fig. 13. (a) Calculated displacement (in $\mathrm{mm}$ ) and (b) calculated displacement where the distortion has been magnified by 2. (c) Difference (20:1) between the theoretical shape and the cross section of a 3D scan of a TiAl part sintered at $1300{ }^{\circ} \mathrm{C}$. (d) Calculated relative density of an optimized object sintered at $1300{ }^{\circ} \mathrm{C}$. 
Overall, the difference between the two is less than $200 \mu \mathrm{m}$, which is quite close to the desired dimensions. However it appears that the top edge of the base of the object (circled in red in Fig. 13) is not fully flat and the measurement shows a slight difference of height of $230 \mu \mathrm{m}$. Fig. 13 (a) and (b) shows the calculated displacement (where the bottom part of the piece is considered fixed) are presented. In Fig. 13 (b), the displacement was artificially enhanced to magnify the distortion effect. A distortion of the top edge of the base is also predicted by the model as illustrated in Fig. 13 (b).

This distortion can be avoided using numerical modeling. To illustrate this, the initial geometry of the counterpart has been optimized geometrically on Comsol in order to reduce the base distortion and the result is presented in Fig. 13 (d). According to the model the object is fully dense at $1300{ }^{\circ} \mathrm{C}$ and the base is fully flat as desired. This shows that the model can be used to anticipate several features in order to design the initial geometry of the counterpart, which could avoid a series of experiments.

It appears that the simulation obtained is very accurate and able to predict several features noticed on the experimental tests. The observation of such peculiar phenomena predicted by the model confirms its veracity and validate the approach developed in this study. Even if a mechanical simulation is always perfectible, the ETM model developed here can be used as an effective predictive tool to anticipate, even for complex geometry, the final shape and density of the desired part.

\section{Conclusions and future work}

A new approach to define the mechanical model of the SPS process is developed in this work. The creep parameters are determined by reverse analysis of the experimental density data. This allows to have rapidly accurate numerical results from a single SPS densification experiment per material. The mechanical model appeared to work for different materials and configurations since the densification of $\mathrm{Al}_{2} \mathrm{O}_{3}$ and TiAl pellets of simple of geometry was accurately predicted for different inner diameter die sizes $(8,20$ and $36 \mathrm{~mm})$.

A fully coupled simulation of the SPS was obtained by combining this mechanical model with the electro-thermal simulation developed in a previous work [12]. This model was tested on a complex shape obtained with the Mobilint approach. The proposed approach seems valid for the set combination of $\mathrm{TiAl}$ and $\mathrm{Al}_{2} \mathrm{O}_{3}$, since the simulation was able to predict both the density and the geometry of both the $\mathrm{Al}_{2} \mathrm{O}_{3}$ counterpart and the TiAl part. The model can be used not only to predict the overall density and geometry of the parts at different temperatures. It is also able to determine the density gradients inside the parts and some complex geometrical features like the curvature of the edges.

Thus, numerical simulation can be effectively used as a predictive tool to better understand the sintering mechanisms of complex shapes. One benefit of the developed method is that it can be applied to identify the creep parameters and easily generalized to a wide range of materials. Sintering complex shapes by SPS introduces new mechanisms compared to simple pellets. Thus, this model can be used to optimize the initial shape in order to anticipate the displacements. From an industrial point of view, numerical simulation is a necessary tool to obtain a fully dense parts with the desired geometry with very limited number of experimental tests.

However, the mechanical model can still be improved. It appears that not only one, but several creep mechanisms are involved in the sintering of materials such as $\mathrm{Al}_{2} \mathrm{O}_{3}$ and TiAl. The next step is to develop a multi-mechanisms approach of the sintering. The fully coupled model and this numerical approach of the mechanical model should also be tested on other materials and complex shapes.

\section{Declaration of Competing Interest}

None.

\section{Acknowledgements}

We thank Norimatfor the technical and financial support. The SPS experiments were performed at the Plateforme Nationale CNRS de Frittage-Flash (PNF2/CNRS Toulouse).

This work was supported by the Association Nationale Recherche Technologie (ANRT)as part of the CIFRE (Industrial Agreement of Formation by Research) contract $n^{\circ} 2017 / 1026$; and the Programme Opérationnel FEDER-FSE Midi-Pyrénées et Garonne 2014-2020as part of the CERAPRINT project $n^{\circ} 17014462$.

\section{References}

[1] S. Grasso, Y. Sakka, G. Maizza, Electric current activated/assisted sintering (ECAS): a review of patents 1906-2008, Sci. Technol. Adv. Mater. 10 (5) (2009), https:// doi.org/10.1088/1468-6996/10/5/053001.

[2] O. Guillon, J. Gonzalez-Julian, B. Dargatz, T. Kessel, G. Schierning, J. Räthel, M. Herrmann, Field-assisted sintering technology/spark plasma sintering: mechanisms, materials, and technology developments, Adv. Eng. Mater. 16 (7) (2014) 830-849, https://doi.org/10.1002/adem.201300409.

[3] R. Chaim, M. Levin, A. Shlayer, C. Estournes, Sintering and densification of nanocrystalline ceramic oxide powders: a review, Adv. Appl. Ceram. 107 (3) (2008) 159-169, https://doi.org/10.1179/174367508X297812.

[4] R. Chaim, R. Marder, C. Estournés, Z. Shen, Densification and preservation of ceramic nanocrystalline character by spark plasma sintering, Adv. Appl. Ceram. 111 (5-6) (2012) 280-285, https://doi.org/10.1179/1743676111Y.0000000074.

[5] E.A. Olevsky, W.L. Bradbury, C.D. Haines, D.G. Martin, D. Kapoor, Fundamental aspects of spark plasma sintering: I. Experimental analysis of scalability, J. Am. Ceram. Soc. 95 (8) (2012) 2406-2413, https://doi.org/10.1111/j.15512916.2012.05203.x.

[6] R. Orrù, R. Licheri, A.M. Locci, A. Cincotti, G. Cao, Consolidation/synthesis of materials by electric current activated/assisted sintering, Mater. Sci. Eng. R Rep. 63 (4-6) (2009) 127-287, https://doi.org/10.1016/j.mser.2008.09.003.

[7] C. Manière, E. Nigito, L. Durand, A. Weibel, Y. Beynet, C. Estournès, Spark plasma sintering and complex shapes: The deformed interfaces approach, Powder Technol. 320 (2017) 340-345, https://doi.org/10.1016/j.powtec.2017.07.048.

[8] M. Bram, et al., Application of electric current assisted sintering techniques for the processing of advanced materials, Adv. Eng. Mater. (2020), https://doi.org/ 10.1002/adem.202000051 p. adem.202000051.

[9] S. Eqtesadi, A. Motealleh, F.H. Perera, P. Miranda, A. Pajares, R. Wendelbo, F. Guiberteau, A.L. Ortiz, Fabricating geometrically-complex $\mathrm{B}_{4} \mathrm{C}$ ceramic components by robocasting and pressureless spark plasma sintering, Scr. Mater. 145 (2018) 14-18, https://doi.org/10.1016/j.scriptamat.2017.10.001.

[10] C. Manière, L. Durand, A. Weibel, G. Chevallier, C. Estournès, A sacrificial material approach for spark plasma sintering of complex shapes, Scr. Mater. 124 (2016) 126-128, https://doi.org/10.1016/j.scriptamat.2016.07.006.

[11] T. Voisin, Exploration de la voie SPS pour la fabrication d'aubes de turbine pour l'aéronautique : Développement d'un alliage TiAl performant et densification de préformes, Université Toulouse 3 - Paul Sabatier, 2014.

[12] A. Van der Laan, V. Boyer, R. Epherre, C. Estournès, Simple method for the identification of electrical and thermal contact resistances in spark plasma sintering, J. Eur. Ceram. Soc. 41 (2020) 599-610, https://doi.org/10.1016/j. jeurceramsoc.2020.08.073.

[13] E.A. Olevsky, Theory of sintering: from discrete to continuum, Mater. Sci. Eng. R Rep. 23 (2) (1998) 41-100, https://doi.org/10.1016/S0927-796X(98)00009-6.

[14] M. Abouaf, J.L. Chenot, G. Raisson, P. Bauduin, Finite element simulation of hot isostatic pressing of metal powders, Int. J. Numer. Methods Eng. 25 (1) (1988) 191-212, https://doi.org/10.1002/nme.1620250116.

[15] J. Chevalier, C. Olagnon, G. Fantozzi, H. Gros, Creep behaviour of alumina, zirconia and zirconia-toughened alumina, J. Eur. Ceram. Soc. 17 (6) (1997) 859-864, https://doi.org/10.1016/S0955-2219(96)00160-4.

[16] J.M. Calderón-Moreno, A.R. de Arellano-López, A. Domínguez-Rodríguez, J. L. Routbort, Microstructure and creep properties of alumina/zirconia ceramics, J. Eur. Ceram. Soc. 15 (10) (1995) 983-988, https://doi.org/10.1016/0955-2219 (95)00070-B.

[17] B. Ratzker, M. Sokol, S. Kalabukhov, N. Frage, Creep of polycrystalline magnesium aluminate spinel studied by an SPS apparatus, Materials (Basel). 9 (6) (2016) 1-9, https://doi.org/10.3390/ma9060493.

[18] B. Ratzker, M. Sokol, S. Kalabukhov, N. Frage, Using a spark plasma sintering apparatus as a tool in a compressive creep study of fine-grained alumina, Ceram. Int. 43 (12) (2017) 9369-9376, https://doi.org/10.1016/j.ceramint.2017.04.106.

[19] G. Bernard-Granger, C. Guizard, Spark plasma sintering of a commercially available granulated zirconia powder: I. Sintering path and hypotheses about the mechanism(s) controlling densification, Acta Mater. 55 (10) (2007) 3493-3504, https://doi.org/10.1016/j.actamat.2007.01.048.

[20] C. Manière, U. Kus, L. Durand, R. Mainguy, J. Huez, D. Delagnes, C. Estournès, Identification of the norton-green compaction model for the prediction of the Ti-6Al-4V densification during the spark plasma sintering process, Adv. Eng. Mater. 18 (10) (2016) 1720-1727, https://doi.org/10.1016/j. actamat.2007.01.048.

[21] C. Manière, L. Durand, A. Weibel, C. Estournès, Spark-plasma-sintering and finite element method: from the identification of the sintering parameters of a 
submicronic $\alpha$-alumina powder to the development of complex shapes, Acta Mater. 102 (2016) 169-175, https://doi.org/10.1016/j.actamat.2015.09.003.

[22] D. Martins, F. Grumbach, A. Simoulin, P. Sallot, K. Mocellin, M. Bellet,

C. Estournès, Spark plasma sintering of a commercial TiAl 48-2-2 powder: densification and creep analysis, Mater. Sci. Eng. A 711 (November) (2017) 313-316, https://doi.org/10.1016/j.msea.2017.11.041, 2018.

[23] D. Martins, F. Grumbach, C. Manière, P. Sallot, K. Mocellin, M. Bellet, C. Estournès, In-situ creep law determination for modeling Spark Plasma Sintering of TiAl 48-2-2 powder, Intermetallics 86 (2017) 147-155, https://doi.org/10.1016/j. intermet.2017.03.006.

[24] C. Wolff, S. Mercier, H. Couque, A. Molinari, Modeling of conventional hot compaction and spark Plasma Sintering based on modified micromechanical models of porous materials, Mech. Mater. 49 (2012) 72-91, https://doi.org/ 10.1016/j.mechmat.2011.12.002.

[25] C. Manière, E.A. Olevsky, Porosity dependence of powder compaction constitutive parameters: determination based on spark plasma sintering tests, Scr. Mater. 141 (2017) 62-66, https://doi.org/10.1016/j.scriptamat.2017.07.026.
[26] E.A. Olevsky, C. Garcia-Cardona, W.L. Bradbury, C.D. Haines, D.G. Martin, D. Kapoor, Fundamental aspects of spark plasma sintering: II. Finite element analysis of scalability, J. Am. Ceram. Soc. 95 (8) (2012) 2414-2422, https://doi. org/10.1111/j.1551-2916.2012.05096.x.

[27] C. Manière, L. Durand, C. Estournès, Powder/die friction in the spark plasma sintering process: modelling and experimental identification, Scr. Mater. 116 (2016) 139-142, https://doi.org/10.1016/j.scriptamat.2016.01.040.

[28] C. Manière, A. Pavia, L. Durand, G. Chevallier, K. Afanga, C. Estournès, Finiteelement modeling of the electro-thermal contacts in the spark plasma sintering process, J. Eur. Ceram. Soc. 36 (February (3)) (2016) 741-748, https://doi.org/ 10.1016/j.jeurceramsoc.2015.10.033.

[29] C. Manière, G. Lee, J. McKittrick, S. Chan, E.A. Olevsky, Modeling zirconia sintering trajectory for obtaining translucent submicronic ceramics for dental implant applications, Acta Mater. 188 (2020) 101-107, https://doi.org/10.1016/j. actamat.2020.01.061. 